it is not identical with $1: 2: 8$ - or any other known trimethylphenanthrene. The formation of a tri- or (tetra-) methylphenanthrene shows that basseol has one of the partial structures I and II. substituted amino-acridines of chemotherapeutic interest, up to 72 per cent yields being obtained compared with 62 per cent yield of proflavine-base which we obtained from unsubstituted $m$-phenylene-

diamine; (b) that meta sub. stituted anilines are most reactive when the substituent is (in descending order of activity) $\mathrm{NH}_{2}$, $\mathrm{N}\left(\mathrm{CH}_{3}\right)_{2}, \quad \mathrm{OH}$ and least active when it is $\mathrm{CH}_{3}$, $\mathrm{Cl}, \mathrm{NO}_{2}, \mathrm{SO}_{3} \mathrm{H}$ or COOH (aniline itself does not react) ; (c)
(I)

The structure (III) suggested for basseol by Ruzicka and Schellenberg ${ }^{2}$ cannot be correct, as this would require the formation of $1: 6$-dimethylphenanthrene on dehydrogenation.

The identification of the dehydrogenation product, which will have a considerable bearing upon the structure of the oleanolic acid group, is now in progress.

University,

J. H. BEynON.

I. M. HeIllbron.

Manchester.

July 29.

${ }^{2}$ Beynon, Heilbron and Spring, $J$. Chem. Soc., 989 (1937).

${ }^{2}$ Ruzicka and Schellenberg, Helv. chim. Acta, 20, 1553 (1937).

${ }^{3}$ Ruzicka, Hösli, and Ehmann, Helv. chim. Acta, 17, 442 (1934).

\section{Preparation of 2:8-Diamino-Acridine}

IT has recently been shown ${ }^{1}$ that amino derivatives of acridine combine high antiseptic potency with low toxicity when the orientation of the amino group $(s)$ is other than the 1- (that is, 9-) position. Unfortunately, the general synthetic methods available for preparing specific amino-acridines involve many stages and are usually wasteful of both time and material $^{2}$, so that a general reaction for converting simple aromatic compounds to amino-acridines in a single operation would give valuable assistance in exploring further the chemotherapy of these compounds.

A hint of the possibility of such a general reaction seems to lie in a patent of 1921 (D.R.P., 347,819) in which a mixture of glycerol, zinc chloride, $m$-phenylenediamine and oxalic acid is stated to give, when heated, a 60 per cent yield of 2 : 8-diamino-acridine, the sulphate of which is the widely used antiseptic proflavine. So far, no investigation of this reaction has appeared in the literature, nor does the patent suggest that it has wider applicability.

Accordingly we decided to investigate: $(a)$ whether substituted $m$-phenylenediamines would take part in this reaction; (b) whether aniline reacted in this way either as such or when variously substituted in the meta position; (c) what the intermediate steps of the reaction are.

The work has reached a stage where an interim report may be made, and our findings to date are : (a) that a variety of substituted meta diamines lend themselves admirably to the production of similarly that the weight of experimental evidence strongly suggests in the case of $m$-phenylene-diamine that the final intermediate is not a diphenyl-methane derivative (as would be expected from analogy with the condensations of formaldehyde with aromatic amines in the production of dihydroacridines) but $3: 3^{\prime}$-diamino-N-formyldiphenylamine. The precursor of the latter compound may be either $3: 3^{\prime}$-diaminodiphenylamine or 3-aminoformanilide, both of which were converted to amino-acridines by this general reaction (in the case of 3 -aminoformanilide the oxalic acid was omitted).

Sections $(a)$ and $(c)$ of the work are still in active progress and a detailed report will appear later.

\section{Adrien Albert. \\ DOROTHY K. LARGE.}

Department of Pharmacy,

University,

Sydney.

July 11 .

1 Albert, Francis, Garrod and Linnell, Brit. J. Exper. Path., 19, 41 (1938); Albert, Dyer and Linnell, Quart. J. Pharm., 10, 649 (1937).

${ }^{2}$ Cf. Albert and Linnell, J. Chem. Soc., 88, 1614 (1936); 22 (1938).

\section{Effect of Desoxycorticosterone and its Esters}

Work carried out in our laboratories ${ }^{1}$ has shown that the output of activity of the male and female sex hormones can be varied almost as desired by suitable esterification. By subcutaneous injection of an oily solution, it can reach quite considerable values ; in particular, the effect of a few days' duration with the free hormone can be raised to several months by using the corresponding esters.

An increase in effect in the above sense has not been observed up to the present with progesterone and its derivatives $^{2}$. It therefore seemed of interest to investigate the effect of 21-oxyprogesterone or desoxycorticosterone, the artificially prepared hormone of the adrenal cortex first synthesized by Steiger and Reichstein ${ }^{3}$. It is known that extracts of the adrenals have only a relatively transitory effect so that, as is the case, for example, with insulin, it must be injected very frequently when used for therapeutic purposes. This permits the assumption that the hormone is quickly degraded in the organism. In order to solve this problem, we are occupied in preparing and investigating, in addition to the already known acetate, a series of other esters of 